\title{
Using Noninvasive Prenatal Testing for Aneuploidies in a Developing Country: Lessons Learnt
}

\author{
Pratima Dash · Ratna D. Puri - Udhaya Kotecha • \\ Sunita Bijarnia $\cdot$ Meena Lall - Ishwar C. Verma
}

Received: 15 October 2014/Accepted: 27 November 2014/Published online: 12 December 2014

(C) Society of Fetal Medicine 2014

\begin{abstract}
The objective of the present study was to analyze the utility of noninvasive prenatal testing (NIPT) for aneuploidies in a developing country like India. NIPT was offered to 500 pregnant women, after review of data of the ongoing pregnancy. Pre-test counseling included the different methodologies of testing, their benefits, limitations, turnaround time and interpretation of the result and was offered to all. Different vendors were used for the test. The results were explained in a post-test counseling session. The indications of NIPT were positive second $(36.6 \%)$ or first (22\%) trimester screen, advanced maternal age with or without positive biochemical screen (24.6\%), ultrasound soft markers $(10.8 \%)$, previous history of Down syndrome $(4.6 \%)$ and anxious couple $(0.1 \%)$. No aneuploidy was detected in 484 samples. In 1 case, no result was available. Fifteen ( $3 \%$ ) cases showed positive results. These included 8 cases of trisomy 21,3 cases of trisomy 18,3 cases of monosomy $\mathrm{X}$, and 1 case of triploidy. Confirmatory testing revealed 6 cases ( $40 \%$ ) to be false positive -1 case of trisomy 21,1 case of trisomy 18,3 cases of monosomy $\mathrm{X}$, and 1 case of triploidy. Of 484 cases, 230 have delivered healthy neonates, while the rest have yet to deliver. Four cases had to discontinue pregnancy due to complications in later pregnancy but unrelated to the NIPT results. Noninvasive prenatal test qualifies as an 'advanced' screening test, and requires invasive diagnostic tests for confirmation of the positive results. The pre- and post-test counseling is essential to appropriately explain the limitations, benefits, and the results to the couple. Recommendations are made for the
\end{abstract}

P. Dash $(\bowtie) \cdot$ R. D. Puri · U. Kotecha · S. Bijarnia · M. Lall · I. C. Verma

Center of Medical Genetics, Sir Ganga Ram Hospital,

Rajinder Nagar 110060, New Delhi, India

e-mail: dr_dprat@yahoo.com appropriate deployment of this new technology in developing countries.

Keywords Noninvasive prenatal test - Aneuploidies . Down syndrome $\cdot$ Screening $\cdot$ Pregnancy $\cdot$ Amniocentesis · Prenatal diagnosis

\section{Introduction}

Intellectual disability (ID) affects about $3 \%$ of the general population and is associated with series of mental and social handicaps. Chromosomal and genetic disorders account for $30-40 \%$ of moderate to severe IDs, of which, Down syndrome is the commonest $[1,2]$. Attempts to detect and prevent the birth of such affected children were initiated in the ' 80 s but were initially limited to women in the advance maternal age. Current recommendations by the American College of Obstetrics and Gynecologists (ACOG) Committee, are that everywoman, regardless of maternal age, should be offered prenatal assessment for aneuploidy either by screening or invasive prenatal diagnosis [3]. Considering the current incidence of Down syndrome to be 1:800, one could estimate that approximately 32,000 babies with Down syndrome are born every year (the birth rate of India is 25.6 million births) [4]. Though screening facilities are currently available in the major cities, expertise in invasive testing is still limited, thus affecting the overall utility of screening. Obstetricians trained in invasive procedures/fetal medicine specialists are few, creating hardship for the high-risk women. There is also the possibility of greater fetal loss due to performance of invasive procedures by less-trained professionals.

In the past few decades, there have been significant advances in the screening methods for aneuploidies [5]. 
Current screening tests have a detection rate of $95 \%$ with a false positive rate of $5 \%$, when maternal age, fetal nuchal translucency (NT), nasal bone, and maternal serum markers like beta human chorionic gonadotropin (b-hCG) and pregnancy associated plasma protein A (PAPP-A) are combined together [6]. However, these tests are not definitive. Women in the high-risk group require confirmatory diagnostic testing either via chorionic villus sampling (CVS) or amniocentesis. These procedures are associated with risk of abortion of $0.2-1 \%$, which may result in the potential loss of a healthy fetus $[7,8]$. This initiated efforts to develop a noninvasive methodology with better sensitivity and specificity, which is now available for clinical use. Termed the noninvasive prenatal testing (NIPT), this technology involves testing the cellfree fetal DNA which is present in the maternal blood [9]. Since its approval, NIPT is being widely offered in the developed countries and is gradually shifting the current screening paradigm [10]. However, there is very little published data regarding its use in developing countries. The authors present their experience of NIPT in the first 500 , and the lessons learnt.

\section{Materials and Methods}

From December 2012 through June 2014, NIPT was offered to 500 patients who presented to the genetic clinic, mostly with positive biochemical screening tests or soft markers detected on ultrasound studies. Pre-test counseling was offered to all women, explaining that NIPT is a highefficiency screening test, but not a diagnostic test. It provides information regarding the presence of only trisomy $21,18,13$, or sex chromosomes abnormalities in the fetus. The turnaround time was explained, along with 1-3\% possibility of resampling risk, if there was inadequate concentration of fetal DNA in the maternal blood sample. The indication for NIPT was determined in each case. Pregnancy data were evaluated to check for previous history of miscarriages or previous children with congenital malformations or mental retardation. Family history was reviewed for evidence of ID or untimely death of a child or any other history suggestive of a single gene disorder. Ultrasound studies were examined to confirm the viability and gestation of the pregnancy, presence of any major malformation, or increased NT or nuchal fold thickness.

Maternal blood samples were collected in a special tube (Streck) and were sent to the laboratory for testing. The authors used different vendors for the test and the samples were analyzed either via massively parallel sequencing (MPS) or analysis based on single nucleotide polymorphisms (SNPs). After learning the benefits, turnaround time, and cost of the analysis of each methodology, patients made an informed decision regarding the type of test. Results of the test were communicated to the couple with post-test counseling. In case of a positive result (aneuploidy detected), confirmation through amniocentesis or CVS was recommended. The fetal sample was analyzed using fluorescence in situ hybridization (FISH) studies as well as culture to obtain a full karyotype. In case of negative results (no aneuploidy detected), reassurance was provided and pregnancy was followed with routine antenatal care till term.

\section{Result}

Noninvasive prenatal test was offered to 500 pregnant ladies. The indication for the test are given in Table 1

Out of 500 samples, 495 samples were tested by MPS and five samples by SNP-based assay. Negative results (no aneuploidy) were obtained in 484 women. Fifteen cases (15/500) showed positive results. No results were obtained in 1 case (1/500), even on repeat sampling.

Cases with negative results were followed through pregnancy to birth. Of 484 cases, 230 have delivered till now and all are unaffected. The rest 250 women are yet to deliver. However, there were 4 cases in which the pregnancy was discontinued due to development of complications unrelated to common chromosomal aneuploidies. These included the following: Case 1: NIPT had been performed at 14 weeks gestation for high first trimester combined risk of trisomy 21 (risk 1:150) and results suggested an unaffected fetus. A level II ultrasound detected shortening of all long tubular bones suggesting the presence of skeletal dysplasia. Amniocentesis revealed a normal karyotype while the mutation analyses for achondroplasia and hypochondroplasia were negative. The family, however, decided to interrupt the pregnancy and refused an autopsy. The second case underwent NIPT at

Table 1 Indication for NIPT, $\mathrm{n}=500$

\begin{tabular}{lll}
\hline Indication & $\begin{array}{l}\text { No. of } \\
\text { patients }\end{array}$ & $\begin{array}{l}\text { Percentage } \\
(\%)\end{array}$ \\
\hline Positive second trimester biochemical screen & 183 & 36.6 \\
$\begin{array}{l}\text { Advanced maternal age with or without high } \\
\text { risk in biochemical screen }\end{array}$ & 123 & 24.6 \\
$\begin{array}{l}\text { Positive first trimester biochemical screen } \\
\text { Ultrasound soft markers like hypoplastic nasal }\end{array}$ & 110 & 22 \\
$\quad$ bone, echogenic focus in heart, choroid & & 10.8 \\
plexus cyst with or without positive & & \\
$\quad$ biochemical screen & 23 & 4.6 \\
$\begin{array}{l}\text { Previous child with Down syndrome } \\
\text { Anxious couple }\end{array}$ & 7 & 0.1 \\
\hline
\end{tabular}


$14+4$ weeks for a high-risk result in the first trimester screen. Although the NIPT showed low risk, the fetus developed congenital cystic adenomatoid malformation (CCAM) at 22 weeks of pregnancy. Karyotype performed on amniotic fluid cells revealed normal chromosomes. The third case spontaneously aborted at 18 weeks due to cervical incompetence. Karyotype of product of conception revealed normal chromosomes. The fourth patient developed pregnancy induced hypertension and there was intrauterine death secondary to increased blood pressure at 32 weeks.

The "positive" NIPT results included 8 cases of Down syndrome, 3 cases of trisomy 18, 3 cases of monosomy $\mathrm{X}$ and 1 case of triploidy. These patients underwent amniocentesis to confirm the same. Brief clinical details of these positive cases are presented in Table 2 .

Seven out of 8 cases reported to be trisomy 21 were confirmed. Of the 6 cases that formed the false positive cohort, 1 was reported as trisomy 21,1 as trisomy 18,3 as monosomy $\mathrm{X}$, and 1 as triploidy/vanishing twin. The false positive cases of trisomy 21 , trisomy 18 and monosomy $\mathrm{X}$ were all analyzed by MPS, while the cases of suspected triploidy were done by SNP-based array. In all the cases of monosomy $\mathrm{X}$, maternal karyotyping was performed and was normal.

\section{Discussion}

The integration of NIPT in current obstetric care at the authors' center has proven to be extremely useful. The commonest indication was high-risk results on biochemical screening (first or second trimester), followed by advanced maternal age, previous child with Down syndrome, or presence of soft markers for aneuploidy in obstetric ultrasound. The major benefit was that 485 (97\%) of 500 cases with negative results did not have to undergo invasive procedures, which averted unnecessary fetal losses. Although sensitivity (detection rate) and specificity (false positive rate) are critical parameters in evaluating a new clinical test, this cannot yet be calculated as 250 women have yet to deliver.

Of the 15 positive cases, $6(40 \%)$ were false positive. This further reinstates that validation of a positive NIPT results is essential, and it is appropriate to classify this as a screening test only. Of the 8 cases positive for trisomy 21 on NIPT, only 1 (12.5\%) was false positive. Of the 3 cases of trisomy 18,1 case (33.3 \%) was false positive, while all the cases of monosomy $\mathrm{X}$ proved to be false positive. All these false positive cases had been tested by MPS. This shows that for the diagnosis of trisomy 18 and certainly for monosomy $\mathrm{X}$, this technology needs to be enhanced. The

Table 2 The clinical features of NIPT positive cases

\begin{tabular}{|c|c|c|c|c|}
\hline Case no. & Indication of NIPT & Aneuploidy detected & Confirmatory test and result & Inference \\
\hline 1 & $\begin{array}{l}\text { Positive first trimester screen. High risk for } \\
\text { trisomy } 21(1: 110)\end{array}$ & Trisomy 21 & Amniocentesis-karyotype, trisomy 21 & True positive \\
\hline 2 & $\begin{array}{l}\text { Positive first trimester screen. High risk for } \\
\text { trisomy } 21(1: 150)\end{array}$ & Trisomy 21 & Amniocentesis—karyotype, trisomy 21 & True positive \\
\hline 3 & Advanced maternal age (42 year) & Trisomy 21 & Amniocentesis—karyotype, trisomy 21 & True positive \\
\hline 4 & $\begin{array}{l}\text { Advanced maternal age (38 year) with positive } \\
\text { triple test for trisomy } 21 \text {, risk } 1: 180\end{array}$ & Trisomy 21 & Amniocentesis—karyotype, trisomy 21 & True positive \\
\hline 5 & Advanced maternal age (40 year) & Trisomy 21 & Amniocentesis—karyotype, trisomy 21 & True positive \\
\hline 6 & Advanced maternal age (39 year) & Trisomy 21 & Amniocentesis—karyotype, trisomy 21 & True positive \\
\hline 7 & Increased NT of $3.5 \mathrm{~mm}$ at CRL of $63 \mathrm{~mm}$ & Trisomy 21 & Amniocentesis—karyotype, trisomy 21 & True positive \\
\hline 8 & Previous child with trisomy 21 & Trisomy 21 & Amniocentesis—karyotype, trisomy 21 & False positive \\
\hline 9 & $\begin{array}{l}\text { IVF pregnancy with positive first trimester } \\
\text { screen for trisomy } 21 \text { (risk }>1: 20 \text { ) with } \\
\text { increased NT of } 2.5 \mathrm{~mm} \text { at CRL of } 57 \mathrm{~mm} \text { ) }\end{array}$ & Trisomy 18 & $\begin{array}{l}\text { Not done as USG at } 16 \text { weeks showed } \\
\text { clenched hands and rocker bottom feet }\end{array}$ & True positive \\
\hline 10 & Advanced maternal age (40 year) & Trisomy 18 & $\begin{array}{l}\text { Not done as USG showed clenched } \\
\text { hands and VSD }\end{array}$ & True positive \\
\hline 11 & Advanced maternal age (39 year) & Trisomy 18 & Amniocentesis-karyotype, normal & False positive \\
\hline 12 & Positive triple test for trisomy 21 (risk $1: 150$ ) & Monosomy X & Amniocentesis-karyotype, normal & False positive \\
\hline 13 & Advanced maternal age (36 year) & Monosomy X & Amniocentesis-karyotype, normal & False positive \\
\hline 14 & $\begin{array}{l}\text { IVF pregnancy with positive triple test for } \\
\text { trisomy } 21 \text { (risk 1:50) }\end{array}$ & Monosomy X & Amniocentesis-karyotype, normal & False positive \\
\hline 15 & $\begin{array}{l}\text { Positive first trimester screen for trisomy } \\
21 \text { (risk 1:140) }\end{array}$ & $\begin{array}{l}\text { Triploidy/Vanishing } \\
\text { twin }\end{array}$ & Amniocentesis-karyotype, normal & False positive \\
\hline
\end{tabular}

$C R L$ crown rump length, $I V F$ in vitro fertilization, $N T$ nuchal translucency $U S G$ ultrasonography, VSD ventricular septal defect 
case, which was false positive for triploidy, was done by SNP-based method. This may have been due to a vanishing twin or placental mosaicism but this cannot be concluded with certainty. Both the techniques for NIPT i.e., MPS and SNP analysis have their advantages and disadvantages. For MPS, the false positive rate for sex chromosome aneuploidies and trisomy 18 is highlighted in the present study. The disadvantage of SNP-based assay is that it is yet to be validated in IVF conception with donor ovum and multiple gestations and hence cannot be currently offered in these indications.

Increased NT is known to be associated with chromosomal anomalies, congenital malformations, recessive single gene disorders, the commonest being Noonan syndrome. Chromosomal aneuploidies account for only $29 \%$ of the cases with increased NT and hence invasive testing should be offered in such cases [11]. In the present cohort of patients, NIPT was performed in 2 cases with increased NT as the involved women were unwilling to undergo invasive testing after understanding the implications of a raised NT.

The other area where NIPT should be used with discretion is in families with obstetric history of recurrent pregnancy losses or with previous children suffering from ID or malformation. In these cases, it is essential to exclude a chromosomal abnormality as an etiological factor. This is because the current technology for NIPT is validated to probe for common chromosomal aneuploidies and is not able to decipher structural and numerical involvement in other chromosomes.

The big debate is whether NIPT should replace the conventional biochemical screening. This deserves attention considering the extended utility of the current screening techniques. Guided by low PAPP-A levels, it is currently possible to predict and initiate management to prevent adverse fetal outcome due to pre-eclampsia. Similarly, an elevated alpha fetoprotein (AFP) not only portends open neural tube defects, it also acts as an indicator for possible development of growth restriction. Low unconjugated estriol raises suspicions of steroid sulfatase deficiency as well as Smith-Lemli-Opitz syndrome.

Secondly, one also needs to consider the cost effectiveness of utilizing NIPT in low-risk situations, though it has been deemed useful in such women [12]. Thus, till NIPT becomes more affordable, it should be limited to the high-risk category.

The advent of NIPT has made testing options more patientfriendly, especially in those who have conceived after in vitro fertilization, multiple pregnancy losses, or in those who have a history of per vaginal bleeding. Earlier in the face of high-risk results, the only method to exclude disease was invasive testing which posed a dilemma for such families.

In the current 'internet savvy' scenario, aggressive promotion of NIPT through electronic media brings along with it, an option of direct-to-consumer testing. This however could be disastrous, especially when in-depth understanding of the technology is lacking leading to its improper application. This has been illustrated through a case that had approached the authors after undergoing such a test. This nonconsanguineous couple had a history of one spontaneous pregnancy loss in the first trimester, one pregnancy interruption due to fetal malformations, and in the current instance, an NIPT had been performed for multiple malformations. The NIPT showed no aneuploidy of the five chromosomes that are usually tested but revealed incidentally, the duplication of a part of chromosome 15, though the exact segment was not specified and no formal written report was issued. The couple had been delivered this information via email and they then approached the authors regarding further course of action. After amniocentesis and culture of the amniotic fluid cells, the fetus was identified to have an unbalanced translocation of chromosome 15 and the mother was confirmed to be a balanced translocation carrier (under publication). This case explicitly demonstrates that the test cannot be used as a 'blanket' for all, but instead there is a need to consider each case individually before recommending such testing. The couple in this case had not only undergone testing which was clinically invalid in their scenario, but also had to bear the trauma of unexpected/incidental findings. Furthermore, one needs to remember that although in this case, the duplication was fortunately detected, failure to do so in other similar situations will lead to disastrous consequences. The NIPT is currently only validated to screen for common chromosomal aneuploidies.

\section{Conclusions}

Noninvasive prenatal test qualifies as an 'advanced' screening test. The potential harms related to its false positive and false negative results are outweighed by its potential benefits. Recently, false negative cases of NIPT have been published $[13,14]$ which again emphasize that even though the sensitivity and specificity of this new technique are high, it is still a screening test and cannot replace the invasive diagnostic tests. The pre- and post-test counseling is essential, and should appropriately explain the limitations, benefits, and the interpretation of the result to the couple. The utility of NIPT is very high if done for correct indications. The acceptance of this test will be greater if the test could be made more economical. In developing countries such as India where the medical expense is not funded by the government or covered by insurance policies, the cost of the test is a crucial factor in the decision making by the couple. Applied selectively, it provides tremendous benefits even in developing countries. 


\section{Conflict of interest None.}

\section{References}

1. Gustavson KH, Hagberg B, Hagberg G, Sars K. Severe mental retardation in a Swedish county. II. Etioiogic and pathogenetic aspects of children born 1959-1970. Neuropadiatrle. 1977;8:293-304.

2. Drillien CM, Jameson S, Wilkinson EM. Studies in mental handicap. Part I: prevalence and distribution by clinical type and severity of defects. Arch Dis Child. 1966;41:528-38.

3. ACOG. ACOG committee on practice bulletins no. 77: screening for fetal chromosomal abnormalities. Obstet Gynecol. 2007; 109(1):217-27.

4. UNICEF website www.unicef.org/infobycountry/india_statistics. html. Accessed 12 Oct 2014.

5. Merkatz IK, Nitowsky HM, Macri JN, et al. An association between low maternal serum alpha-fetoprotein and fetal chromosome abnormalities. Am J Obstet Gynecol. 1984;148:886-94.

6. Cuckle H, Benn P. Multi-analyte maternal serum screening for chromosomal defects. In: Milunsky A, Milunsky JM, editors. Genetic disorders and the fetus: diagnosis, prevention and treatment. 6th ed. Chichester: Wiley-Blackwell; 2010. p. 771-818.

7. ACOG. ACOG practice bulletin no. 88, December 2007. Invasive prenatal testing for aneuploidy. Obstet Gynecol. 2007;110: 1459-67.
8. Alfirevic Z, Sundberg K, Brigham S. Amniocentesis and chorionic villus sampling for prenatal diagnosis. Cochrane Database Syst Rev. 2003;3:CD003252.

9. Yu SC, Chan KC, Zhang J, Hui AB, Wong N, Lau TK, et al. Size distributions of maternal and fetal DNA in maternal plasma. Clin Chem. 2004;50:88-92.

10. Chitty LS, Bianchi DW. Non-invasive prenatal testing: the paradigm is shifting rapidly. Prenat Diagn. 2013;33(6):511-3.

11. Nicolaides KH. Nuchal translucency and other first-trimester sonographic markers of chromosomal abnormalities. Am J Obstet Gynecol. 2004;191:45-67.

12. Bianchi DW, Parker RL, Wentworth J, Madankumar R, Saffer C, Das AF, Craig JA, Chudova DI, Devers PL, Jones KW, Oliver K, Rava RP, Sehnert AJ, CARE Study Group. DNA sequencing versus standard prenatal aneuploidy screening. N Engl J Med. 2014;370(9):799-808.

13. Smith M, Lewis KM, Holmes A, Visootsak J. A case of false negative NIPT for Down syndrome-lessons learned. Hindawi Publishing Corporation. Case Reports in Genetics, 2014, Article ID 823504.

14. McCullough RM, Almasri EA, Guan X, Geis JA, Hicks SC, Mazloom AR, et al. Non-invasive prenatal chromosomal aneuploidy testing-clinical experience: 100,000 clinical samples. PLoS One. 2014;9(10):e109173. 